\title{
Anti-NMDA Encephalitis: A Rare Encephalitis in a Child- A Case Report
}

\section{Saurav Khetan ${ }^{1}$, Nikhil Agrawal ${ }^{1}$ and Prakash Rajoli ${ }^{2}$}

${ }^{1}$ Department of Paediatrics, Nepalese Army Institute of Health Sciences, Shree Birendra Hospital, Chhauni, Kathmandu, Nepal

${ }^{2}$ Province Hospital, Surkhet, Nepal

\begin{abstract}
Anti-NMDA encephalitis is second commonest cause of autoimmune encephalitis among children; however, it is hardly diagnosed and often not considered as one of the differentials when a child presents with encephalitis-related symptoms. In children, it presents mostly with seizures or psychiatric symptoms without prodrome. Here we present a six years old girl who presented with seizures and inappropriate behaviour. We investigated her in the line of viral encephalitis such as Japanese Encephalitis, which is very common in our region. However, results were not suggestive of Japanese Encephalitis and further investigations subsequently lead to diagnosis of anti- NMDA encephalitis. This is probably one of the first case report of this disease in our country. We want to highlight the significance of high index of suspicion for looking out for an organic cause in any child who presents with psychiatric symptoms, along with seizures.
\end{abstract}

Key words: Anti-NMDA encephalitis; autoimmune encephalitis; seizures

Correspondence: Saurav Khetan, Department of Paediatrics, Nepalese Army Institute of Health Sciences, Shree Birendra Hospital, Chhauni, Kathmandu, Nepal. E-mail address: drsauravkhetan@gmail.com

DOI: http://dx.doi.org/10.3126/mjsbh.v19i2.28666

Submitted on: 2020-04-30

Accepted on: 2020-05-12 


\section{INTRODUCTION}

Anti N-Methyl-D-Aspartate Receptor (NMDAR) encephalitis is a synaptic autoimmune condition., ${ }^{1,2}$ It is considered second commonest cause of autoimmune encephalitis after acute disseminated encephalomyelitis among children and adolescents. $^{1}$

It is more common among females during adolescence and among males in children younger than 12 years. It presents in a highly unpredictable manner with psychiatric symptoms like anxiety, agitation, bizarre behaviour, mood disturbances and catatonic features. ${ }^{1}$ The mortality rate is as high as $25 \%$ and there is resolution of the disease if diagnosed and managed early during the course of illness. Hence, if any child presents with different neuropsychiatric symptoms, NMDAR encephalitis must also be kept in mind. So far, there has been no such case report from our country and this is probably the first diagnosed case from our country.

\section{CASE REPORT}

A six years girl, second product of non consanguineous marriage, with no significant past history and developmentally normal child presented to our OPD with seizures. She had single episode of tonic posturing of body associated with up rolling of eye balls and clenching of teeth lasting for about five to seven minutes and followed by postictal confusion. She was initially evaluated at local hospital and managed as a case of seizure with sodium valproate. Her baseline investigations and neuroimaging were normal, EEG was suggestive of epileptic changes. After a few days, she developed bizarre behaviour, aggression, abnormal body posturing and insomnia in her home. For these symptoms, she was brought to our institute and during the stay, she had numerous such episodes ranging from 25 seconds to five minutes. Initially she was managed as meningoencephalitis and was evaluated for possible behavioural disorders and child abuse. Her CSF study ruled out bacterial and viral infections (Japanese Encephalitis and Herpes Simplex virus). As she did not show improvement and her abnormal behaviour worsened, the possibility of anti NMDA encephalitis was considered. Hence, repeat CSF study using IFA was done which came positive for NMDA receptor antibody and EEG showed diffuse delta slowing suggestive of diffuse encephalopathic process. Thus, she was diagnosed as anti NMDA receptor encephalitis and was treated with IVIG at dosage of $400 \mathrm{mg} / \mathrm{kg} /$ day and IV methylprednisolone at dosage of $24 \mathrm{mg}$ in three divided doses for five days followed by oral prednisolone at $15 \mathrm{mg}$ dose for 30 days. She showed drastic improvement with treatment and finally she was discharged after a month. Her steroid dose was tapered during the course of her regular monthly follow up.

\section{DISCUSSION}

Anti NMDA receptor encephalitis is autoimmune disorder first described by Dalmau and colleagues in 2007 among 12 women as paraneoplastic condition. $^{2}$ It is a rare disorder with very low incidence and the prevalence in children is exactly unknown. Remy KE et al. reported more than 600 cases including paediatric ones and Goldberg EM reported 577 cases with $37 \%$ children. ${ }^{3,4}$ In children, it may present as young as three months of age but the mean age of presentation 9.98 years. It is one and half times more common among females and $17.6 \%$ of female patients had ovarian teratoma. ${ }^{4}$ In this disease, antibodies are produced against NR1 subunit of the NMDA receptor present in postsynaptic membrane of neurons. ${ }^{1}$ These antibodies cause reversible decrement in the surface density and synaptic localisation of NMDAR clusters via antibody-mediated capping and internalisation. ${ }^{5}$ This results in clinical features of encephalitis.

In adults, it manifests in three clinical stages; a prodromal stage, an early (psychotic and/or seizure phase), and a late (hyperkinetic) phase. ${ }^{4}$ In children, it presents mostly with psychiatric symptoms. ${ }^{1}$ Prodromal stage lasts for few days to two weeks and presents as viral infection like symptoms. Following prodrome, early phase manifests with psychiatric or seizure activity and later progressing to deterioration in the consciousness, disintegration of speech and language, mutism, irritability, catatonia, and autonomic instability within next three to four weeks. ${ }^{1,4,6}$ If treated, patient's recovery occurs with symptoms in reverse manner. ${ }^{4}$

Early diagnosis and treatment has full or near full recovery among up to $75-80 \%$ of cases. ${ }^{1,5}$ Its definitive diagnosis is done by demonstrating anti- 
NMDAR receptors in either CSF or serum with higher sensitivity $(100 \%$ vs $85 \%)$ of former one. ${ }^{1}$ CSF study usually reveals lymphocytic pleocytosis (in $87 \%$ of cases) and oligoclonal bands (in $60 \%$ of cases). ${ }^{4}$ Only antibody titre in CSF has correlation with the disease severity. ${ }^{7}$ Brain MRI is abnormal in $35 \%$ of cases with non specific cortical and subcortical hyperintense signal abnormalities in T2. 1,6 Follow-up imaging may reveal cerebral atrophy. ${ }^{6}$ A characteristic "extreme delta brush" EEG pattern characterised by beta-delta complexes are seen in paediatric patients (53\% of cases). ${ }^{1,8}$ EEG has higher sensitivity (96\%) than that of brain MRI(33\%) or serum anti-NMDAR antibodies (87\%).EEG study having normal posterior rhythm in first recording has better prognostic value. ${ }^{8}$

Its treatment among paediatric patients focuses on empirical use of immunotherapies along with correction of any underlying causes. ${ }^{1,6}$ First-line therapies include IVIG therapy $(400 \mathrm{mg} / \mathrm{kg} /$ day for five days or $1000 \mathrm{mg} / \mathrm{kg} /$ day on day one followed by $500 \mathrm{mg} / \mathrm{kg} / \mathrm{day}$ for next two days), high-dose methylprednisolone (30 to $40 \mathrm{mg} / \mathrm{kg} /$ day for three days) or plasma exchange daily for six cycles. In refractory cases or critically ill patients, second-line immunomodulation with rituximab $\left(375 \mathrm{mg} / \mathrm{m}^{2}\right.$ weekly for four weeks) or cyclophosphamide (750 $\mathrm{mg} / \mathrm{m}^{2}$ monthly for four to six months). ${ }^{1,4}$ Relapse are common up to $25 \%$ among patients. ${ }^{6,7}$ Relapsed episodes are usually milder than first one and immunotherapy has same effectiveness. ${ }^{1}$ To decrease the relapse rates, immunosuppressive therapy with mycophenolate or azathioprine for a year is recommended. ${ }^{7}$

\section{CONCLUSIONS}

Anti-NMDAR encephalitis is increasingly recognised for having debilitating psychiatric and neuromotor dysfunction in children if not treated promptly. Although its diagnosis is challenging in children due to lack of its classic presentation, but if diagnosed and treated early, full recovery is achievable. Early diagnosis, immunotherapy, and malignancy work-up and correction are the mainstays of management. This case highlights the need for clinicians to consider the possibility of anti-NMDAR encephalitis in patients who present with encephalitis-suggestive symptoms and no specific findings on routine neuroimaging, EEG, or CSF analysis.

\section{ACKNOWLEDGEMENT}

We would like to thank parents of patients for providing consent for the publication of case report.

To cite this article: Khetan S, Agrawal N, Rajoli P. Anti-NMDA Encephalitis: A Rare Encephalitis in a Child- A Case Report. MJSBH. 2019;19(2);108-11.

Conflict of Interest: None declared

\section{REFERENCES}

1. Kliegman RM, Stanton BM, Geme JS, Schor NF. Nelson Textbook of Pediatrics E-Book: 2-Volume Set. Elsevier Health Sciences; 2015 Apr 17.

2. Rong X, Xiong Z, Cao B, Chen J, Li M, Li Z. Case report of anti-N-methyl-D-aspartate receptor encephalitis in a middle-aged woman with a long history of major depressive disorder. BMC psychiatry. 2017;17(1):320. DOI: $10.1186 / \mathrm{s} 12888-017-1477-\mathrm{x}$

3. Goldberg EM, Titulaer M, de Blank PM, Sievert A, Ryan N. Anti-N-methyl-D-aspartate receptor-mediated encephalitis in infants and toddlers: case report and review of the literature. Pediatr Neurol. 2014;50:181-4. DOI: 10.1016/j.pediatrneurol.2013.10.002

4. Remy KE, Custer JW, Cappell J, Foster CB, Garber NA, Walker LK, et al. Pediatric anti-N-methyl-D-aspartate receptor encephalitis: a review with pooled analysis and critical care emphasis. Front paedatr. 2017;5:250. DOI: 10.3389/fped.2017.00250 
5. Coffey MJ, Cooper JJ. Electroconvulsive therapy in anti-N-methyl-D-aspartate receptor encephalitis: a case report and review of the literature. The journal of ECT. 2016;32(4):225-9. DOI: 10.1097/YCT.0000000000000334

6. Kim EH, Kim YJ, Ko TS, Yum MS, Lee JH. A young child of anti-NMDA receptor encephalitis presenting with epilepsia partialis continua: the first pediatric case in Korea. Korean J Pediatr. 2016;59(1):133. DOI: 10.3345/kjp. 2016.59.11.S133

7. Matoq AA, Rappoport AS, Yang Y, O'Babatunde J, Bakerywala R, Sheth RD. Anti-NMDA-receptor antibody encephalitis in infants. Epilepsy behav case rep. 2015;4:99-101. DOI: 10.1016/j.ebcr.2015.07.005

8. Van Sonderen A, Arends S, Tavy DL, Bastiaansen AE, De Bruijn MA, Schreurs MW, et al. Predictive value of electroencephalography in anti-NMDA receptor encephalitis. J Neurol Neurosurg Psychiatry. 2018;89(10):1101-6. DOI: 10.1136/jnnp-2018-318376.

9. Balu R, McCracken L, Lancaster E, Graus F, Dalmau J, Titulaer MJ. A score that predicts 1-year functional status in patients with anti-NMDA receptor encephalitis. Neurology. 2019;92(3):244-52. DOI: 10.1212/WNL. 0000000000006783 